\title{
Analiza możliwości rozbudowy pojemności czynnej podziemnego magazynu gazu w wyniku podnoszenia górnego ciśnienia pracy PMG powyżej pierwotnego ciśnienia złoża gazu
}

\begin{abstract}
Pierwsze próby magazynowania gazu ziemnego przeprowadzono na początku XX wieku. Obecnie w różnych krajach eksploatowanych jest prawie sześćset podziemnych magazynów gazu (PMG). Magazyny budowane są w celu zaspokajania potrzeb rynkowych. Niektóre pracują dla systemu dystrybucyjnego, inne dla systemu przesyłowego, jeszcze inne pełnią role strategiczne. Większość z nich wybudowana została w sczerpanych złożach gazu ziemnego i ropy naftowej, inne powstały w warstwach wodonośnych i kawernach solnych. Znane są przypadki budowy PMG w wyrobiskach górniczych. Pojemność czynna każdego podziemnego magazynu gazu zależy od wielkości złoża, zakresu ciśnień jego pracy oraz od panujących w nim warunków hydrodynamicznych. Zmiana pojemności czynnej magazynu może nastąpić tylko poprzez zmianę zakresu ciśnień jego pracy, gdyż pozostałe parametry, określone dla danego złoża, pozostają stałe. Według danych American Gas Association (AGA) powiększenie pojemności czynnej w wyniku podniesienia górnego ciśnienia pracy magazynu jest dość częstym zjawiskiem. Według danych AGA około 54\% magazynów eksploatowanych jest z górnym ciśnieniem nieprzekraczającym pierwotnego ciśnienia złożowego. Stosowanie ograniczeń ciśnieniowych wynika z faktu, że szczelność złoża jest potwierdzona do pierwotnego ciśnienia złożowego. Jednakże magazynowanie gazu pod wyższym ciśnieniem jest możliwe, o czym świadczy eksploatacja 46\% wszystkich PMG, których górne ciśnienie pracy przewyższa pierwotne ciśnienie złożowe. Niniejszy artykuł przedstawia problem bezpiecznego podnoszenia górnego ciśnienia pracy PMG wytworzonych w złożach wyeksploatowanych.
\end{abstract}

Słowa kluczowe: magazyny gazu, PMG, ciśnienie w PMG, eksploatacja PMG.

\section{Analysis of the possibility of expanding an underground gas storage facility working volume by raising the upper UGS operating pressure above the original gas reservoir pressure}

\begin{abstract}
The first attempts to store natural gas were carried out at the beginning of the $20^{\text {th }}$ century. At present, there are almost six hundred UGS facilities in different countries. Gas storages are built to meet market needs. Some work for the distribution system, others for the transmission system, and others are strategic. Most of them were built in depleted natural gas and crude oil fields, others in aquifers and salt geological structures. There are some cases of building UGS in mining excavations. The active capacity of each underground gas storage, depends on the size of the reservoir, the pressure range of its operation and the hydrodynamic conditions existing in the field. The enlargement of gas storage working volume can be achieved by changing the operating pressure range. According to the American Gas Association (AGA), increasing operating capacity as a result of raising the upper operating pressures of a gas storage is a quite common occurrence. About $54 \%$ of storages are operated with the pressure not exceeding the original reservoir pressure. The application of pressure limitations results from the fact that the tightness of the reservoir is confirmed to the original field pressure. However, it is possible to store gas at a higher pressure, as evidenced by the exploitation of $46 \%$ of all UGS, whose upper operating pressure exceeds the original reservoir pressure. This article presents the problem of the safe rising of natural gas storage operating pressure.
\end{abstract}

Key words: UGS, gas storage, storage operation pressure, working volume, storage in natural gas fields. 


\section{Analiza dotychczasowej pracy PMG pod kątem możliwości powiększenia jego pojemności czynnej}

Pojemność czynna każdego magazynu gazu zależy od wielkości złoża, zakresu ciśnień jego pracy oraz od panujących w nim warunków hydrodynamicznych. Zmiana pojemności czynnej magazynu może nastąpić tylko poprzez zmianę zakresu ciśnień jego pracy, gdyż pojemność całkowitą magazynu określa wielkość pułapki złożowej. Pierwotne zasoby geologiczne przykładowego złoża wynosiły około $2062 \mathrm{mln} \mathrm{m}^{3}$ gazu ziemnego, natomiast pierwotne ciśnienie złożowe było równe 12,19 MPa (rysunek 1). Obecna pojemność czynna PMG wynosi $500 \mathrm{mln} \mathrm{m}^{3}$, natomiast pojemność całkowita magazynu to $V c=1062 \mathrm{mln} \mathrm{m}^{3}$, przy ciśnieniu złożowym $P d s=12,3 \mathrm{MPa}$. Można zauważyć, że obecna pojemność całkowita magazynu jest o $1000 \mathrm{mln} \mathrm{m}^{3}$ mniejsza od zasobów pierwotnych horyzontu magazynowego, jednakże ciśnienie złożowe (12,3 MPa) jest prawie równe ciśnieniu początkowemu $(12,19 \mathrm{MPa})$. W związku z tym dalsza rozbudowa magazynu będzie wymagała przekroczenia pierwotnego ciśnienia złożowego.

PMG

Wykres zmian cisnienia głowicowego Pgs w zalezności od pojemności całkowitej magazymu $V_{c}$

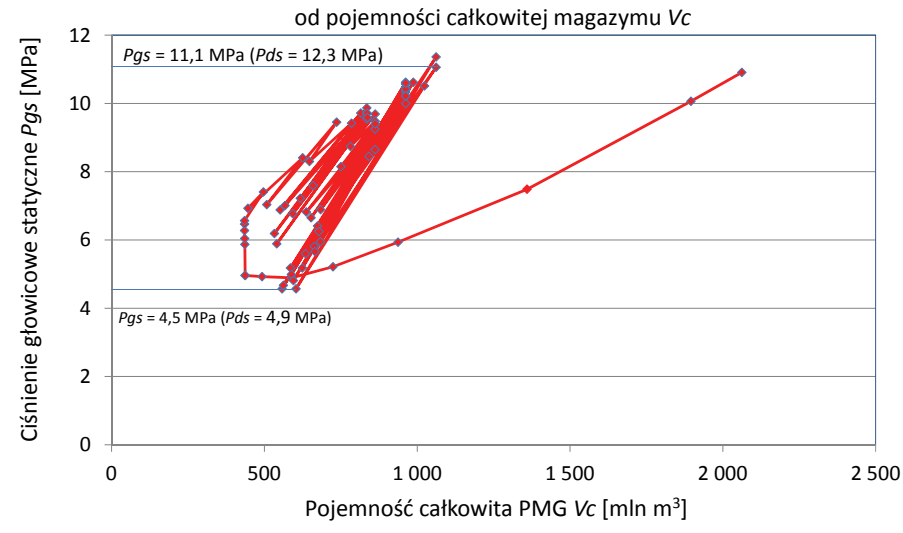

Rys. 1. Wykres zmian ciśnienia podczas eksploatacji przykładowego złoża i PMG (opracowanie własne)

Zgodnie z publikacją American Gas Association (AGA) powiększenie pojemności czynnej w wyniku podniesienia górnego ciśnienia pracy magazynu jest dość częstą praktyką [1]. Bardzo ważny wskaźnik związany z magazynowaniem gazu to stosunek górnego ciśnienia eksploatacji PMG ( $P d s g$ ) do pierwotnego ciśnienia złożowego występującego przed rozpoczęciem eksploatacji złoża gazu ziemnego ( $P d s o)$. Rysunek 2 prezentuje liczbę magazynów gazu, ujętą procentowo, w zależności od wielkości $P d s g / P d s o$. Według danych AGA około 54\% PMG eksploatowanych jest z górnym ciśnieniem nieprzekraczającym pierwotnego ciśnienia złożowego. Stosowanie ograniczeń ciśnieniowych wynika z faktu, że szczelność złoża jest potwierdzona do pierwotnego ciśnienia złożowego. Jednakże magazynowanie gazu pod wyższym ciśnieniem jest możliwe, gdyż pozostałe 46\% PMG wytworzonych w wyeksploatowanych złożach gazu ziemnego i ropy naftowej pracuje z górnym ciśnieniem przekraczającym pierwotne ciśnienie złożowe. Analizując wykres, można również zauważyć, że około 34\% wszystkich PMG pracuje z górnym ciśnieniem zawierającym się w przedziale $1,1 \div 1,3$ krotności pierwotnego ciśnienia złożowego. Biorąc pod uwagę analizę AGA oraz aktualne parametry eksploatacji PMG, można stwierdzić, że istnieje możliwość dalszej rozbudowy pojemności czynnej analizowanego magazynu. Należy jednakże pamiętać, że przewyższenie pierwotnego ciśnienia złożowego podczas pracy PMG wymaga przeprowadzenia szczegółowych badań, potwierdzających szczelność struktury (złoża).

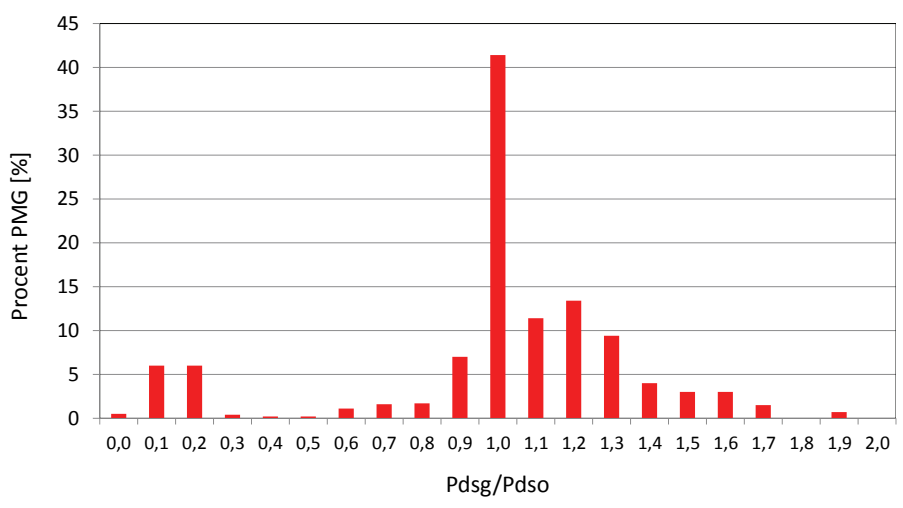

Rys. 2. Porównanie górnego ciśnienia pracy PMG $(P d s g)$ do pierwotnego ciśnienia złożowego ( $P d s o)$ [1]

Rozbudowa pojemności czynnej każdego magazynu wymaga wykonania analizy możliwości zagospodarowania dodatkowej pojemności magazynowej przez rynek. Rysunek 3 przedstawia zmianę pojemności czynnej PMG oraz stopień jej wykorzystania, począwszy od roku 2000. W okresie 2001-2014 pojemność czynna magazynu wynosiła $400 \mathrm{mln} \mathrm{m}^{3}$. Na rysunku można zauważyć, że stopień wykorzystania pojemności czynnej w latach 2000-2017 wynosił co najmniej 70\%. Wyjątkiem od tej reguły był okres 2013-2014, gdy stopień sczerpania magazynu był równy około $30 \%$ pojemności czynnej.

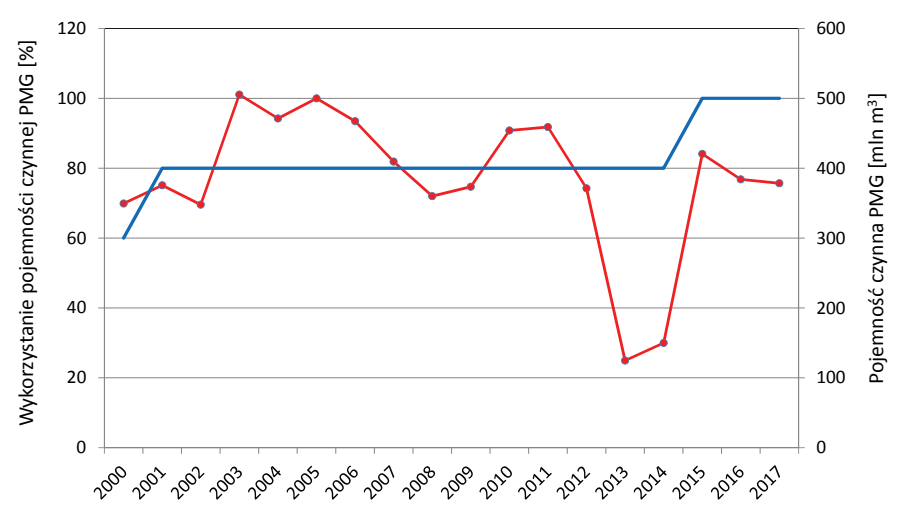

Rys. 3. Wykres wykorzystania pojemności czynnej PMG w latach 2000-2017 (opracowanie własne) 
Należy podkreślić, że w 2007 roku wprowadzono ustawę z dnia 16 lutego 2007 roku o zapasach ropy naftowej, produktów naftowych i gazu ziemnego oraz zasadach postępowania w sytuacjach zagrożenia bezpieczeństwa paliwowego państwa i zakłóceń na rynku naftowym, na mocy której każdy importer gazu ziemnego sprzedawanego w Polsce musi utworzyć zapas obowiązkowy gazu, pozostający w dyspozycji ministra do spraw energii. Wielkość zapasu obowiązkowego odpowiada 30-dniowej średniej wielkości importu gazu w całym roku. W związku z tym, począwszy od 2007 roku, część pojemności PMG została zarezerwowana na „zapas obowiązkowy” [7]. Konsekwencją tego stanu było niższe sczerpywanie pojemności magazynu. Biorąc pod uwagę wielkość zapasu obowiązkowego zmagazynowanego w PMG, można stwierdzić, że cała handlowa pojemność czynna była sczerpywana z cyklu na cykl. W związku z tym rynek pokazuje, że mógłby zagospodarować większą pojemność czynną analizowanego PMG.

Jak już wcześniej stwierdzono, każda rozbudowa PMG musi uwzględniać zachowanie szczelności struktury geologicznej poprzez niedopuszczenie do rozszczelnienia skał złożowych [3].

\section{Analiza możliwości podniesienia górnego ciśnienia pracy wykonana pod kątem rozszczelnienia skał złożowych}

Publikacja AGA wykazała, że 46\% podziemnych magazynów gazu pracuje z górnym ciśnieniem przekraczającym pierwotne ciśnienie złożowe. Patrząc na rysunek 2, można zauważyć, że maksymalne górne ciśnienie magazynu może przewyższać ciśnienie pierwotne nawet o 90\%. W związku z tym podstawową analizą, jaka powinna zostać wykonana przed planowanym podniesieniem górnego ciśnienia pracy magazynu, jest określenie granicznego ciśnienia, które nie spowoduje rozszczelnienia skał zbiornikowych. Jednoznaczną odpowiedź można uzyskać dopiero po zbudowaniu modelu geomechanicznego danego złoża [2, 3]. Poprawna budowa modelu geomechanicznego wymaga przeprowadzenia:

- badań złożowych, wykonania w odwiercie leak of test (mikroszczelinowań);

- badań laboratoryjnych, określenia ciśnienia szczelinowania dla skał złożowych;

- badań geofizycznych pozwalających na określenie naprężeń pionowych $[6,8]$.

Niestety w Polsce do tej pory nie przywiązywano wagi do budowy modeli geomechanicznych dla PMG, gdyż dotychczas złożowe magazyny gazu pracowały w zakresie ciśnień nieprzekraczających wartości ciśnień pierwotnych. W związku z tym brak jest danych umożliwiających wykonanie precyzyjnego modelu geomechanicznego dla PMG. Niemniej jednak M. Jarosiński określił ciśnienie szczelinowania dla skał miocenu zalegających na różnej głębokości (rysunek 4). Na rysunku można zauważyć, że ciśnienie wymagane do wykonania szczelinowania (mini fracs) w zakresie głębokości PMG

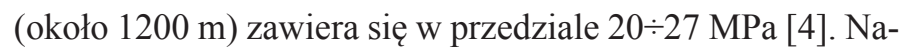
leży podkreślić, że pierwotne ciśnienie złożowe w horyzoncie magazynowym wynosiło 12,19 MPa. Wysoka wartość ciśnienia szczelinowania w porównaniu do ciśnienia hydrostatycznego jest przyczyną tego, że jedna trzecia wszystkich podziemnych magazynów gazu przewyższa pierwotne ciśnienie złożowe do $30 \%$. Badania AGA wykazały, że podniesienie górnego ciśnienia pracy magazynu o $20 \%$ jest bezpiecznym zabiegiem, który daje wymierne korzyści ekonomiczne.

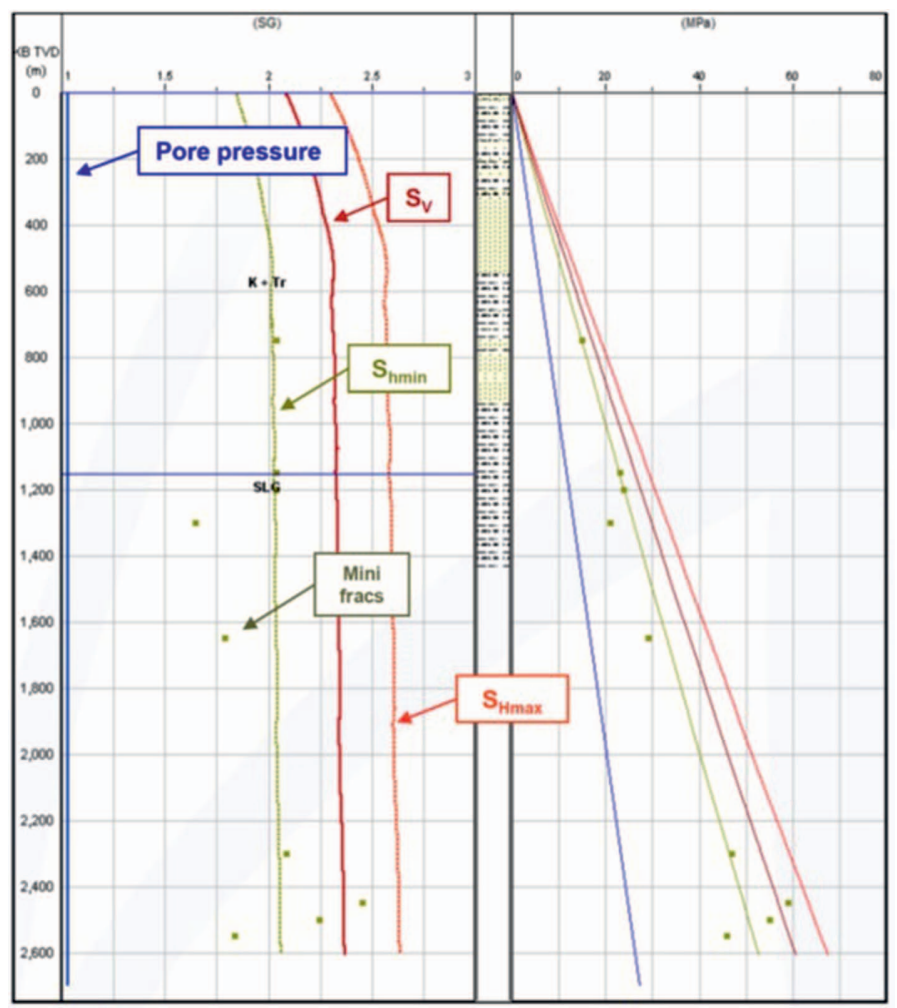

Rys. 4. Ciśnienie szczelinowania dla skał miocenu zalegających na różnej głębokości [4]

\section{Określenie maksymalnej pojemności czynnej PMG oraz koniecznej wielkości buforu}

Maksymalna pojemność czynna możliwa do wytworzenia w PMG zależy tylko i wyłącznie od górnego i dolnego ciśnienia pracy magazynu. Jak już wcześniej stwierdzono, dal- sze powiększanie pojemności czynnej PMG wymaga przekroczenia pierwotnego ciśnienia złożowego. W celu pokazania wpływu górnego ciśnienia pracy PMG na wielkość pojemności 
czynnej założono, że górne ciśnienie pracy PMG będzie o 20\% wyższe od ciśnienia pierwotnego. Zgodnie z analizami przedstawionymi w opracowaniu AGA przekroczenie pierwotnego ciśnienia złożowego o 20\% nie stwarza żadnych zagrożeń dla dalszej pracy magazynu [2]. Biorąc pod uwagę powyższe założenie, można stwierdzić, że górne maksymalne ciśnienie pracy PMG będzie wynosić około Pdsg = 14,6 MPa. Szacunkowe obliczenia wykazały, że zatłaczając gaz do górnego ciśnienia pracy PMG, w złożu będzie można zmieścić około $V c=1540 \mathrm{mln} \mathrm{m}^{3}$. W związku z tym pojemność czynna magazynu będzie zależna od wielkości buforu. Przyjmuje się, że w magazynach złożowych średnia wielkość buforu stanowi około 50\% pojemności całkowitej magazynu [5]. Można zatem uznać, że podniesienie górnego ciśnienia pracy PMG o 20\% spowoduje wzrost pojemności czynnej magazynu do wielkości $770 \mathrm{mln} \mathrm{m}^{3}$. Zgodnie z przeprowadzonymi obliczeniami można również stwierdzić, że zakres ciśnień pracy PMG po rozbudowie pojemności czynnej do wielkości $V a=770 \mathrm{mln} \mathrm{m}^{3}$ będzie wynosił $P d s=14,6 \div 7,2 \mathrm{MPa}$.

Należy podkreślić, że przedstawione parametry zostały określone w sposób szacunkowy. W związku z tym decyzja o rozbudowie pojemności czynnej do wielkości maksymalnej powinna zostać poprzedzona szczegółową analizą geomechaniczną, złożową i ekonomiczną.

\section{Podsumowanie}

Według danych American Gas Association około 46\% wszystkich magazynów gazu wytworzonych w wyeksploatowanych złożach gazu ziemnego i ropy naftowej pracuje z górnym ciśnieniem przewyższającym pierwotne ciśnienie złożowe. $Z$ tego $34 \%$ wszystkich magazynów eksploatowanych jest z górnym ciśnieniem pracy przekraczającym pierwotne ciśnienie złożowe o wielkości od $10 \%$ do $30 \%$. Badania AGA wykazały, że podniesienie górnego ciśnienia magazynowania o 20\% w stosunku do pierwotnego ciśnienia złożowego jest bezpiecz- nym zabiegiem, który daje wymierne korzyści. Niemniej jednak każde przewyższenie pierwotnego ciśnienia powinno zostać poprzedzone odpowiednią analizą złożową oraz geomechaniczną. W artykule przedstawiono analizę rozbudowy PMG opartą na założeniu podniesienia górnego ciśnienia pracy magazynu o $20 \%$. Wykonane obliczenia pokazały, że podniesienie górnego ciśnienia pracy magazynu pozwala na zwiększenie pojemności czynnej do wielkości około $770 \mathrm{mln} \mathrm{m}^{3}$. Natomiast wielkość buforu będzie wynosić $V b=770 \mathrm{mln} \mathrm{m}^{3}$.

\section{Wnioski}

1. Badania AGA wykazały, że zwiększenie górnego ciśnienia magazynowania o $20 \% \mathrm{w}$ stosunku do pierwotnego ciśnienia złożowego jest zabiegiem bezpiecznym.

2. Każde podniesienie ciśnienia magazynowania, szczególnie powyżej pierwotnego ciśnienia złożowego, powinno zo- stać poprzedzone odpowiednią analizą złożową oraz geomechaniczną.

3. Podniesienie górnego ciśnienia pracy analizowanego przykładowego PMG o 20\% pozwoli na zwiększenie pojemności czynnej magazynu o $270 \mathrm{mln} \mathrm{m}^{3}$.

Prosimy cytować jako: Nafta-Gaz 2018, nr 4, s. 279-283, DOI: 10.18668/NG.2018.04.03

Artykuł nadesłano do Redakcji 23.11.2017 r. Zatwierdzono do druku 5.03.2018 r.

\section{Literatura}

[1] Bruno M.S., Dewolf G., Foh S.: Geomechanical analysis and decision analysis for delta pressure operations in gas storage reservoirs. Proc. AGA Operations Conf., Denver, CO, 7-9.05.2000.

[2] Bruno M.S., Dusseault M.B., Balaa T.T., Barrera J.A.: Geomechanical Analysis of Pressure Limits For Gas Storage Reservoirs. Paper USA-328-5, presented at the North American Rock Mechanics Symposium, NARMS '98, 3-5.06.1998.

[3] Bruno M.S., Lao K., Diessl J., Xiang J., White N., van der Veer E.: Development of Improved Caprock Integrity Analysis and Risk Assessment Techniques. Paper presented at the $12^{\text {th }}$ International Conference on Greenhouse Gas Technologies (GHGT), Austin, TX, 6-9.10.2014.

[4] Jarosiński M.: Wspótczesny reżim tektoniczny w Polsce na podstawie analizy testów szczelinowania hydraulicznego ścian otworów wiertniczych. Przegląd Geologiczny 2005, vol. 53, nr 10/1, s. 863-872.

[5] Kravanja S., Žlender B.: Optimal design of underground gas storage. Fifth International Conference on High Performance Structures and Materials, Tallinn 2010. DOI: 10.2495/HPSM100361.
[6] Nauroy J.-F., Baroni A., Guy N.: Geomechanical Study for Castor Gas Storage. IFP -Energies Nouvelles, Report \#62034, 2011.

[7] Rokosz W., Filar B.: Możliwości tworzenia zapasu obowiązowego gazu w Podziemnych Magazynach Gazu. Nafta-Gaz 2010, nr 5, s. $352-355$.

[8] Słota-Valim M.: Seismic and well log data as a source for the calculation of elastic properties of rock media-conditioning for successful exploration, well trajectory, completion and production design of unconventional reservoirs. Nafta-Gaz 2013, nr 8, s. 583-587.

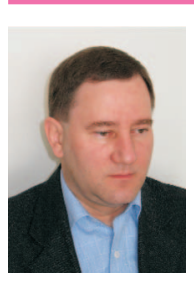

Mgr inż. Bogdan FILAR

Starszy specjalista badawczo-techniczny; kierownik Zakładu Podziemnego Magazynowania Gazu. Instytut Nafty i Gazu - Państwowy Instytut Badawczy ul. Lubicz 25 A

31-503 Kraków

E-mail: bogdan.filar@inig.pl 